\title{
Problematic risk-taking involving emerging technologies: A stakeholder framework to minimize harms
}

\author{
THOMAS B. SWANTON ${ }^{1 *}$, ALEX BLASZCZYNSKI ${ }^{1}$, CYNTHIA FORLINI $^{2,3}$, \\ VLADAN STARCEVIC ${ }^{4,5}$ and SALLY M. GAINSBURY ${ }^{1}$ \\ ${ }^{1}$ School of Psychology, Science Faculty, Brain \& Mind Centre, Gambling Treatment \& Research Clinic, \\ The University of Sydney, Camperdown, NSW, Australia \\ ${ }^{2}$ Faculty of Medicine and Health, School of Public Health, Sydney Health Ethics, The University of Sydney, \\ Sydney, NSW, Australia \\ ${ }^{3}$ Faculty of Health, School of Medicine, Deakin University, Geelong, VIC, Australia \\ ${ }^{4}$ Faculty of Medicine and Health, Sydney Medical School, Nepean Clinical School, Discipline of Psychiatry, \\ The University of Sydney, Sydney, NSW, Australia \\ ${ }^{5}$ Department of Psychiatry, Nepean Hospital, Penrith, NSW, Australia
}

(Received: July 18, 2019; revised manuscript received: August 22, 2019; accepted: August 23, 2019)

\begin{abstract}
Background and aims: Despite the many benefits of technological advancements, problematic use of emerging technologies may lead to consumers experiencing harms. Substantial problems and behavioral addictions, such as gambling and gaming disorders, are recognized to be related to Internet-based technologies, including the myriad of new devices and platforms available. This review paper seeks to explore problematic risk-taking behaviors involving emerging technologies (e.g., online gambling and gaming, online sexual behaviors, and oversharing of personal information via social networking sites) that have the potential to lead to problematic outcomes for individuals. Results and discussion: Previous research has focused on policy frameworks for responding to specific issues (e.g., online gambling), but a broader framework is needed to address issues as they emerge, given lags in governments and regulators responding to dynamically evolving technological environments. In this paper, key terms and issues involved are identified and discussed. We propose an initial framework for the relative roles and responsibilities of key stakeholder groups involved in addressing these issues (e.g., industry operators, governments and regulators, community groups, researchers, treatment providers, and individual consumers/end users). Conclusion: Multidisciplinary collaboration can facilitate a comprehensive, unified response from all stakeholders that balances individual civil liberties with societal responsibilities and institutional duty of care.
\end{abstract}

Keywords: online risk-taking, emerging technologies, behavioral addictions, consumer protection

\section{INTRODUCTION}

Since the 1990s, rapid technological advancements have enabled consumers to communicate via the Internet in novel ways, with increased speed and accessibility, and across multiple platforms. These technologies have created benefits for consumers, including greater opportunities for social interaction, access to information, and entertainment. However, the factors and technologies that make the Internet useful and important, including accessibility, affordability, and anonymity, can also increase consumers' risk of involvement in activities and behaviors that may result in negative and/or problematic outcomes. Technological developments that facilitate enhanced access to online content and communication have been associated with Internet-based behaviors including online gambling and gaming, social media use, and accessing sexual content. Emerging technologies such as computers, smartphones, and wearable devices are tools that enable consumers to gain constant access to these activities through various platforms.
Debate exists regarding which online behaviors are problematic, as well as whether such problems represent an endpoint along a continuum or a categorically distinct entity reflecting a non-substance behavioral addiction. Complicating the issue, the direction of causality remains obscure, given that some online behaviors represent coping mechanisms, masking underlying mental health problems such as depression and anxiety. Accordingly, how problems are defined, and the threshold cut-off points used to differentiate heavy from problematic engagement often remain vague and are not necessarily dependent on degree of engagement. Problems can be situated on a continuum from minor and transient through to serious and persistent impacts on users or recipients, with arbitrary threshold

* Corresponding author: Thomas B. Swanton; Research Assistant; School of Psychology, Science Faculty, Brain \& Mind Centre, Gambling Treatment \& Research Clinic, The University of Sydney, 94 Mallett Street, Camperdown, NSW 2050, Australia; Phone: +61 9114 4157; E-mail: thomas.swanton@sydney.edu.au

This is an open-access article distributed under the terms of the Creative Commons Attribution-NonCommercial 4.0 International License, which permits unrestricted use, distribution, and reproduction in any medium for non-commercial purposes, provided the original author and source are credited, a link to the CC License is provided, and changes - if any - are indicated. 
markers often based on subjective or normative judgments. In addition, problems can be identified by different individuals using different criteria, for example, by the consumer themselves or significant others (e.g., a parent expressing concerns about the behaviors of their child/adolescent).

Behaviors with the potential for serious harms include Internet-mediated gambling, online gaming, sexual behaviors (e.g., viewing pornography and exchanging explicit photos and messages), online shopping, and sharing of personal information through social media. These behaviors may be socially acceptable to varying degrees and are generally non-criminal and non-hostile in nature when non-excessive. Some of these activities are regulated (e.g., online gambling, privacy laws controlling the collection and dissemination of personal information), but many are not [e.g., online gaming, viewing pornography (except child pornography), and online shopping]. Similarly, service providers may have to comply with specific regulations, such as licensing requirements for gambling operators, but others fall under more general consumer frameworks and legislation. Online gaming and cybersex, for example, are not strictly or specifically regulated, despite being consistently associated with a range of negative health-related outcomes (King \& Delfabbro, 2018; Männikkö, Ruotsalainen, Miettunen, Pontes, \& Kääriäinen, 2017; Wéry \& Billieux, 2017). Prevalence of problematic risk-taking behaviors is challenging to measure given the lack of verified assessment tools and so estimates typically vary widely, ranging from $5.6 \%$ to $9.6 \%$ for problematic cybersex (Wéry \& Billieux, 2017), and from $1 \%$ to $15 \%$ for gaming disorder/addiction (Saunders et al., 2017).

Harms associated with use of a variety of online content types have emerged as an important social issue. A multitude of theoretical frameworks exist for conceptualizing and responding to specific problematic issues in the context of gambling (e.g., Blaszczynski, Ladouceur, \& Shaffer, 2004), gaming (e.g., Király et al., 2018; Starcevic, 2017), sexual behaviors (e.g., Gola \& Potenza, 2018; Wéry \& Billieux, 2017), general Internet overuse (e.g., Lopez-Fernandez, 2015; Starcevic \& Billieux, 2017), social media use (e.g., Lee, Ho, \& Lwin, 2017), online aggression/bullying (e.g., Aboujaoude, Savage, Starcevic, \& Salame, 2015), and others. However, these frameworks are issue- or activityspecific. A strategic policy framework for addressing this broad area of concern is lacking. Such a framework is necessary to guide proactive responses to issues as they emerge given the inherent difficulties for governments and regulators in dealing with the rapidly changing and increasingly globalized technological environment.

This discussion paper adopts a multidisciplinary approach in seeking to identify the key terms and issues relating to problematic risk-taking involving emerging technologies. The term "emerging technologies" is used to avoid limiting the debate to specific existing technologies, recognizing the dynamic nature of the field and the ongoing development of products and activities. The label "problematic risk-taking" is used intentionally to avoid reference to addiction, which, although an important topic for debate, is not the focus of this paper. Our focus is on behavior, rather than a specific product or activity, as harms typically stem from how these are used, taking into consideration the influences of product design and environment.
Individual consumers/end users, families, community groups, treatment and welfare providers, researchers, industry, and government have roles to play in responding to these issues. Thus, a secondary aim is to create an initial set of guiding principles for the development and implementation of policies that protect individuals and communities from associated harms and promote healthy patterns of online behavior. The relative responsibilities of key stakeholder groups are considered. This paper intends to encourage collaboration between all stakeholders and eventually lead to a comprehensive, unified response that balances individual civil liberties with societal responsibilities and institutional duty of care.

\section{Defining problematic risk-taking involving emerging technologies}

Emerging technologies refer to the broad range of infrastructure and devices, which may facilitate access to the Internet or otherwise change the way in which existing activities are undertaken. The Internet is one type of virtual communication network. "Infrastructure" denotes the basic facilities, such as fiber optic cabling and wireless Internet, which affect the speed, availability, and penetration of virtual communication. "Devices" are the physical products that are required for individuals to access and engage with the virtual communication network, and include laptops, smartphones, tablets, smart watches, gaming consoles, and virtual reality headsets. In addition to accessing content, individuals can communicate with others using services such as e-mail, instant messaging, chat rooms, and social networking sites. Individuals' online behaviors are related to the devices they use, which rely on the infrastructure that supports the Internet.

Emerging technologies are not limited to those involving the Internet. Blockchain and cryptocurrency, for example, can be considered as emerging technologies as they facilitate new modes of transacting. Artificial intelligence and machine learning-based technologies involve new methods for businesses to engage in highly personalized marketing of specific product offerings to targeted consumers. Virtual reality and wearable devices create new ways to access and experience data and activities. As technologies are dynamic and constantly evolving, we define emerging technologies and their uses to incorporate those which have already emerged, are in the process of emerging, or will emerge in the future. Our focus is on the ways in which these technologies are used, and the features of their design that may have framing effects on consumer decisions about engagement in particular behaviors. Hence, this paper will focus on the behavioral and decision-making aspects of problematic risk-taking involving emerging technologies.

Risk-taking broadly involves engagement in a specific action or making a decision after consciously or heuristically estimating the probability of a particular outcome and consequences occurring as a result of that action or decision. Engagement in some degree of risky activity is an inevitable part of normal human life. However, risk-taking may become problematic when engagement leads the individual and/or others to experience harms. In the context of the online environment, problematic risk-taking is defined as 
engaging with online content in a way that compromises the individual, leading her/him to experience harms. Problematic risk-taking can be contrasted with non-problematic risk-taking. For example, non-problem gambling still involves risk-taking but is not associated with harms.

In our view, the distinction between non-problematic and problematic online risk-taking behaviors is not categorical for most behaviors. Instead, these behaviors exist on a continuum, defined by the level of risk of experiencing harms associated with risk-taking behavior. In some cases, excessive engagement may be positively associated with increased risk of experiencing harms. Protective behaviors, such as using privacy settings on social networking sites to limit others' access to content posted or placing time and/or monetary limits on accounts, may offset the level of risk. While there is no clear cut-off for problematic risk-taking, it entails assessment of the presence of indicators of harm. For example, while an individual may not assess their own activity to be problematic, clear indicators of harm, such as poor personal hygiene, lack of sleep, lack of engagement in physical and offline social activities, and monetary losses that reduce ability to pay for necessities, may suggest that the behavior has already become problematic. The conception of problematic risk-taking on a continuum reflects the pattern of the individual cycling in and out of experiencing harms. This avoids attributing harms as inherent characteristics of the individual or the activity, as can be reflected by terms like "problem gamer." Instead, someone experiencing harms as a consequence of excessive online gaming is seen as being "engaged in problematic gaming."

Positioning risk-taking on a continuum is related to a multidisciplinary approach to the issue. For example, traditional economic approaches, as described by the expected utility hypothesis (Bernoulli, 1954), suggest a categorical definition for problematic risk-taking: any decision that results in a suboptimal outcome. Applying psychological principles to understand decision-making under risk demonstrates the complexities underlying these decisions and behaviors, particularly considering how individual differences shape behavioral responses to the same stimuli. Sociological approaches seek to understand the experience for groups or individuals, while public health approaches examine the impact of problematic risk-taking on broader communities or populations. The field of behavioral economics demonstrates that the way in which information is presented can influence risky decision-making. This suggests that while individuals may seek to make informed decisions about the activities in which they engage, their responses may be influenced by the way that information is framed to them (Tversky \& Kahneman, 1981). From a mental health perspective, problematic risk-taking behavior has been regarded as an aspect of a personality temperament dimension such as novelty seeking (Cloninger, Svrakic, \& Przybeck, 1993) and as one of the key features of a dimensionally conceptualized impulsivity (Hollander \& Evers, 2001). Beyond personality, a complex set of interacting physiological, motivational, cognitive, and affective factors (e.g., interoception, executive function, associative learning, and social cognition) also underlie the decisionmaking processes involved (Rochat, Maurage, Heeren, \& Billieux, 2019). Theories relevant to this complex issue are numerous and exist across disciplines, and further in-depth consideration of the value and intersection of these various theories are necessary. These selected examples do not represent an exhaustive list, but rather indicate how approaching the same issue from multiple perspectives can yield vastly different paradigms of a common phenomenon (e.g., Racine \& Forlini, 2010). An interdisciplinary approach can prevent blind spots and unforeseen consequences of a unilateral approach to guide the development of productive interventions and policies that minimize harms.

Adding to the complexity of this issue, the experience of harms in the context of problematic risk-taking behaviors may be due to comorbid mental disorders. The causal relationship between mental disorders and problematic risk-taking may not be straightforward, although it is often assumed that some mental disorders (e.g., impulse-controlrelated disorders or bipolar disorders) lead to problematic risk-taking. For this reason, the true extent of harms experienced as a direct result of problematic risk-taking, not attributable to a mental disorder, is largely unknown.

\section{Key stakeholder groups and their relative roles and responsibilities in harm minimization}

Although the ultimate decision to engage in an activity is made by the individual, the responsibility for adequate consumer protection rests with multiple stakeholders. This is not to attribute responsibility solely to the individual or deflect responsibility from providers. Governments and industry have a responsibility to develop and implement strategies that are effective in protecting consumers from the harms associated with problematic risk-taking behaviors and which promote healthy and balanced engagement. Researchers should work collaboratively across disciplines and involve end users and other stakeholders to understand emerging risks and problematic behavior, and design and test ways to enhance well-being and minimize harms. Treatment and welfare providers need to recognize relevant problems as they emerge in society and implement appropriate screening and treatment strategies. Communities, families, and individuals should be educated about risks related to technologies that they or significant others use, the potential associated harms, and ways to minimize these harms.

Technologies already exist and continue to emerge that allow individuals to engage in risky activities, but policy lags behind, allowing individuals and communities to experience harms associated with problematic engagement. There is a need for collaborative efforts to develop and implement policy informed by empirical research, incorporating insights from a range of different disciplines. Policy should be constructed with measurable outcomes for monitoring, accountability, and evaluation of effectiveness. It must cater for people across the lifespan; however, a focus on youth is strategic for promoting the establishment of healthy patterns of engagement.

Table 1 sets out a preliminary framework for the relative roles and responsibilities of key stakeholder groups in minimizing harms associated with problematic risk-taking involving emerging technologies. This framework is not intended to be exhaustive; rather, it identifies those groups 
Table 1. Relative roles and responsibilities of key stakeholder groups in minimizing harms associated with problematic risk-taking involving emerging technologies

\begin{tabular}{|c|c|c|}
\hline Stakeholder group & Definition of stakeholder group & Roles and responsibilities \\
\hline Individuals & $\begin{array}{l}\text { End users or consumers engaged in potentially } \\
\text { problematic risk-taking behaviors }\end{array}$ & $\begin{array}{l}\text { Ownership of ultimate decision about the extent of engagement } \\
\text { in a behavior } \\
\text { Due consideration of information provided from a variety of } \\
\text { sources concerning potential risks } \\
\text { Use of available tools to aid self-regulation and minimize } \\
\text { exposure to potential harms }\end{array}$ \\
\hline Families & $\begin{array}{l}\text { Parents/caregivers of children/adolescents } \\
\text { engaged in potentially problematic } \\
\text { risk-taking behaviors }\end{array}$ & $\begin{array}{l}\text { Education about risks and communicating these to family } \\
\text { members } \\
\text { Setting guidelines around use of emerging technologies and } \\
\text { assisting to abide by these } \\
\text { Decisions about providing funds and assistance with managing } \\
\text { finances for engagement with emerging technologies } \\
\text { Monitoring of behavior and risk markers } \\
\text { Role modeling of how to engage with technology to enhance } \\
\text { well-being }\end{array}$ \\
\hline Community & $\begin{array}{l}\text { Frontline groups (e.g., teachers, police, and } \\
\text { advocacy organizations) that have contact } \\
\text { with individuals engaged in potentially } \\
\text { problematic risk-taking behaviors }\end{array}$ & $\begin{array}{l}\text { Education and awareness of the potential risks to individuals' } \\
\text { health and well-being, and ways in which technology use } \\
\text { may cause harm to others, particularly vulnerable populations } \\
\text { (e.g., online exploitation of children) } \\
\text { Promoting methods to establish healthy and sustainable } \\
\text { patterns of engagement } \\
\text { Developing and implementing education campaigns and } \\
\text { prevention strategies to be used by community members } \\
\text { Reporting of emerging patterns and trends in behaviors } \\
\text { observed }\end{array}$ \\
\hline $\begin{array}{l}\text { Treatment and welfare } \\
\text { providers }\end{array}$ & $\begin{array}{l}\text { Non-specialist and specialist clinicians who } \\
\text { provide treatment and support services to } \\
\text { individuals engaged in potentially } \\
\text { problematic risk-taking behaviors }\end{array}$ & $\begin{array}{l}\text { Identification and detection of emerging problematic behaviors } \\
\text { amongst vulnerable populations } \\
\text { Provision of treatment and support services through the } \\
\text { development of effective, evidence-based therapeutic } \\
\text { modalities for individuals engaging in problematic risk- } \\
\text { taking behaviors, especially if there are co-occurring mental } \\
\text { disorders }\end{array}$ \\
\hline Researchers & $\begin{array}{l}\text { Academics and scientists from a range of } \\
\text { disciplines (e.g., psychology, psychiatry, } \\
\text { behavioral economics, neuropsychology, } \\
\text { public health, media and communications, } \\
\text { and sociology) whose work relates to } \\
\text { problematic risk-taking involving emerging } \\
\text { technologies }\end{array}$ & $\begin{array}{l}\text { Investigating the true nature and scope of emerging issues } \\
\text { Informing and evaluating policy and treatment approaches } \\
\text { Working with all stakeholders to design and conduct } \\
\text { methodologically rigorous, independent research } \\
\text { Translating research findings and theoretical developments to } \\
\text { guide policies and strategies to enhance well-being and } \\
\text { minimize harms }\end{array}$ \\
\hline Industry & $\begin{array}{l}\text { Any organizations profiting, either directly or } \\
\text { indirectly, from technologies and products } \\
\text { involved with problematic behaviors, } \\
\text { including product developers, distributors, } \\
\text { advertisers, broadcasters, and trade } \\
\text { associations }\end{array}$ & $\begin{array}{l}\text { Public recognition of potential for technologies to be used in } \\
\text { ways that lead to harms } \\
\text { Clear user guidelines on appropriate and inappropriate use of } \\
\text { technologies and behaviors that may lead to harms } \\
\text { Development, implementation, and evaluation of harm- } \\
\text { minimization strategies (e.g., in-app tools and resources) } \\
\text { appropriate to potential risks } \\
\text { Detection of emerging problematic behaviors through } \\
\text { identification of consumers exhibiting risky patterns of } \\
\text { behavior (e.g., by predictive modeling) for potential } \\
\text { preventative action or intervention, including referral to } \\
\text { treatment and support services as appropriate } \\
\text { Demand reduction: e.g., increasing product prices and } \\
\text { provision of alternative options } \\
\text { Accountability, transparency, and willingness to collaborate } \\
\text { with other stakeholder groups in response to emerging } \\
\text { problematic behaviors relating to their products }\end{array}$ \\
\hline
\end{tabular}


Table 1. (Continued)

\begin{tabular}{lcc}
\hline Stakeholder group & \multicolumn{1}{c}{ Definition of stakeholder group } & Roles and responsibilities \\
\hline Governments & $\begin{array}{c}\text { Government bodies responsible for policy and } \\
\text { regulation relating to problematic risk-taking } \\
\text { involving emerging technologies } \\
\text { (e.g., gambling regulators) }\end{array}$ & $\begin{array}{c}\text { Public recognition of risky behaviors resulting in harms from } \\
\text { use of emerging technologies } \\
\text { Facilitation of prevention strategies and treatment services, } \\
\text { including provision of funding to appropriate stakeholders } \\
\text { Development of classification strategies to reduce access to } \\
\text { inappropriate technologies or products by minors } \\
\text { Supply reduction through development, implementation, } \\
\text { monitoring, and evaluation of policies for limiting the } \\
\text { availability of content and activities that have the potential for } \\
\text { problem development }\end{array}$ \\
& $\begin{array}{c}\text { Demand reduction: e.g., through increased taxation of } \\
\text { particular products } \\
\text { Creating a regulatory environment in which industry can } \\
\text { proactively disclose potentially problematic behaviors } \\
\text { detected without fear of negative consequences to allow } \\
\text { investigation and promote early intervention }\end{array}$ \\
\hline
\end{tabular}

that have a clear role to play and is proposed to provide a launchpad for further multidisciplinary research and collaboration between stakeholder groups. It is important to recognize that this framework approaches the issue with a Western cultural lens through which individuals are largely viewed as responsible for their actions (with some notable exceptions, such as children or persons deemed mentally incompetent). It will be necessary to apply a different cultural lens for these issues in non-Western cultures, as the conceptualization of problematic behaviors and mental disorders and the systems and stakeholder groups (e.g., policy makers and treatment providers) that exist to address these issues are inseparable from their cultural context (Marsella \& Yamada, 2010).

\section{DISCUSSION}

Technology use is almost universal and emerging technologies have a rapid movement from early adoption to mainstream use. Despite many benefits, there are increasing ways in which individuals can experience harms resulting from inappropriate use of technologies. All stakeholders need to recognize this reality. Collaboration across stakeholders is necessary to address problematic behaviors related to emerging technologies. Simultaneously, it is important to recognize the differing agendas and interests of each stakeholder group, including differences within groups. Some perspectives are divergent or inherently incompatible (e.g., individual vs. public perspectives) but need to be addressed to enable effective dialogue and collaboration toward reduction of a mutually recognized problem.

There are many issues that are beyond the scope of this paper. The level of social justice policies that are appropriate to protect vulnerable groups such as minors and those with compromised mental competencies is an aspect of our framework that must be negotiated. For others, the principle of autonomy generally supports that individuals ought to be able to make their own choices. A central tenet is that individuals must be provided the requisite information about the potential harms and benefits associated with a product to make appropriate decisions (i.e., informed choice). Such information must be timely, accurate, readily understood, not exploitative through misleading or deceptive claims, and readily accessible. However, the issue of the provision of this information (e.g., how it is delivered, how accurate it is, and how it is to be monitored) remains to be clarified.

In the context of emerging technologies, informed consent requires full and open disclosure to be made by product providers. Failure to inform consumers of the probability of events, likelihood of outcomes, the precise outcomes to be expected from purchases, or in-game mechanics including how outcomes are determined can comprise effective decision-making and subsequently represent exploitative practices. From a social justice perspective, attention should be directed toward vulnerable groups, such as minority subpopulations who may have limited knowledge or capacity to comprehend or access information, and those with mental health difficulties that impair decision-making. Here, providers must be especially cognizant of the need to include and display information in clear and concise formats, and to offer information regarding ancillary services and resources that might be utilized if problems emerge.

Particular difficulties are associated with determining the roles, expectations, and responsibilities of significant others managing family members who exhibit problematic behaviors, as is often the situation with individuals with substance abuse and mental health issues. Parents and guardians have obligations in relation to protecting and ensuring the health and well-being of minors. However, conflicts emerge where individuals of age have poor insight into their problematic risk-taking behaviors and resist the efforts of others attempting to offer support. Options for the development of protocols to allow collaborative efforts with significant others should be considered by governments and industry. For example, governments in China have mandated operators to suspend or limit game playing times among youth. Other options include providers monitoring and 
suspending excessive activities on their sites. Cross-cultural differences in familial and societal expectations, as well as in approaches to public policy, need to be carefully considered in the development and tailoring of specific strategies to ensure their feasibility, acceptability, and effectiveness. For example, in their systematic review of international policy strategies targeting problematic gaming and Internet use, King et al. (2018) note that while the South Korean model of gaming disorder prevention is "an exemplar of a coordinated response to a public health threat" (p. 246), it cannot be indiscriminately transposed to different cultural contexts, which inevitably have their own unique sociocultural factors to take into account.

Greater regulation or monitoring may be required for industry groups given the potential to use unacceptable strategies to manipulate or deceive consumers, thereby reducing the ability of consumers to make informed decisions. Such regulatory measures have been imposed on the gambling industry, which faces strict monitoring and standards to ensure products are provided in a fair manner. However, there are claims that many aspects of regulated products still create inducements. Developing more effective ways to provide consumers with appropriate information to enable informed choice requires more research and evaluation. Despite legislative requirements in most jurisdictions and a substantial body of research, most gamblers are still poorly informed about the likelihood of winning prizes and about the way in which outcomes are determined.

Initial key issues for further academic inquiry include investigating emerging behavioral patterns relating to technology use and examining the potential for problematic risk-taking behaviors with particular emerging technologies. This includes studying the structural features of technologies associated with problem development or exacerbation; understanding the theoretical bases for problematic behaviors and the decision-making processes involved; establishing the prevalence, social determinants, harms, and outcomes associated with problematic behaviors; and empirically evaluating the effectiveness of policies and interventions.

This paper is intended to highlight the importance of interdisciplinary collaboration to the ongoing discussion and debate surrounding problematic use of emerging technologies. Although there remain many unanswered and important questions regarding problems and harms, it is important to strive toward a focus on how to enhance consumer well-being. The value of the proposed framework is that it applies at a broader level than isolated examination of one specific issue, and can therefore act to guide proactive collaborative responses from key stakeholders to issues as they emerge. All stakeholders have the potential to gain enormous benefits from technological developments. Retaining focus on wellbeing and the potential advantages to be gained may be helpful for framing a collaborative dialogue across stakeholders to ensure that strategies to minimize harm are implemented.

Funding sources: This work was supported by an Australian Research Council Discovery Early Career Research Award (DE1060100459) awarded to Associate Professor Sally Gainsbury.
Authors' contribution: SMG, AB, CF, and VS conceptualized the paper and provided further input and edits. TBS drafted the manuscript. All authors reviewed and approved the final version of the manuscript for submission.

Conflict of interest: Over the past 5 years (2015-2019), Dr. SMG has worked on projects that have received funding and in-kind support through her institution from Australian Research Council, NSW Liquor and Gaming, Victorian Responsible Gambling Foundation, National Association for Gambling Studies, Manitoba Gambling Research Program, Star/Echo Entertainment, Svenska Spel Research Council, Responsible Wagering Australia, Australian Communication and Media Authority, Commonwealth Bank of Australia, National Association for Gambling Studies, GameCo, ClubsNSW.

Dr. SMG is currently a member (2019-2020) of the National Council on Problem Gambling International Advisory Board (Singapore) and receives an honorarium for this role as well as travel expenses to attend an annual meeting. She is a member of the Steering Committee for Remote Gambling Research and the Independent Research Oversight Panel both run by GambleAware, which provide an honorarium.

She has received honorariums directly and indirectly for research, presentations and advisory services from Credit Suisse, Oxford University, ClubsNSW, Clubs4Fun, Centrecare WA, Gambling Research Exchange Ontario, Crown, Department of Social Services, Community Clubs Victoria, Financial and Consumer Rights Council, Australian Communications and Media Authority, Manitoba Gambling Research Program, VGW Holdings, Nova Scotia Provincial Lotteries and Casino Corporation, British Columbia Lottery Corporation, Gambling Research Australia, Responsible Gambling Trust, Ministry of Health, Clayton Utz, Greenslade, Generation Next.

She has also received travel expenses to attend meetings from Franklin Women, GambleAware, Community Clubs Victoria, Centrecare WA, Financial and Consumer Rights Council, Stiftelsen Nordiska Sällskapet för Upplysning om Spelberoende, Generation Next, Alberta Gambling Research Institute, QLD Treasury, British Columbia Lottery Corporation, Responsible Gambling Council.

All professional dealings have been conducted with the aim of understanding gambling, enhancing responsible gambling and harm-minimization policies and practices as well as treatment interventions. All research had human research committee ethics approval. Funding bodies had no opportunity to influence the collection, analysis, or interpretation of data.

For the period 2015-2019, Prof. AB has conducted research funded directly by Australian or international government, or government-related funding agencies, and industry operators. These include Gambling Research Exchange Ontario, ClubsNSW, Dooleys Club Lidcombe, Aristocrat Leisure Industries, Australian Communications Media Authority, Gaming Technologies Association, Gambling Research Australia, Responsible Wagering Australia, Commonwealth Bank, NSW Department of Trade 
and Investment (NSW Office of Liquor, Gaming and Racing), La Loterie Romande (Switzerland), Camelot (United Kingdom), La Française des Jeux (France), Loto-Quebec (Canada), and National Lottery (Belgium), and the National Association for Gambling Studies. He is on the responsible gambling advisory panel for Crown Casino.

He has received honorariums from Manitoba Gambling Research Program and GambleAware (formerly UK Responsible Gambling Trust) for grant reviews, and royalties from several publishers for books and book chapters. He has also received travel and accommodation expenses from Leagues Clubs, Crown Casino, Gambling Research Exchange Ontario, USA National Council on Problem Gambling, Japan Medical Society for Behavioural Addiction, Le Comité d'organisation Congrès international sur les troubles addictifs, Victorian Responsible Gambling Foundation, North American Association of State and Provincial Lotteries, and New Horizons (British Columbia Lottery Corporation to attend conferences and meetings.

All professional dealings have been conducted with the aim of enhancing responsible gambling and harmminimization policies and practices, training counsellors in the treatment interventions, and advancing our understanding of the psychology of gambling.

TBS, Dr. CF, and Assoc. Prof. VS declare no conflict of interest.

\section{REFERENCES}

Aboujaoude, E., Savage, M. W., Starcevic, V., \& Salame, W. O. (2015). Cyberbullying: Review of an old problem gone viral. Journal of Adolescent Health, 57(1), 10-18. doi:10.1016/j. jadohealth.2015.04.011

Bernoulli, D. (1954). Exposition of a new theory on the measurement of risk. Econometrica, 22(1), 23-36. doi:10.2307/ 1909829

Blaszczynski, A., Ladouceur, R., \& Shafer, H. J. (2004). A sciencebased framework for responsible gambling: The Reno model. Journal of Gambling Studies, 20(3), 301-317. doi:10.1023/B: JOGS.0000040281.49444.e2

Cloninger, C. R., Svrakic, D. M., \& Przybeck, T. R. (1993). A psychobiological model of temperament and character. Archives of General Psychiatry, 50(12), 975-990. doi:10.1001/archpsyc. 1993.01820240059008

Gola, M., \& Potenza, M. N. (2018). Promoting educational, classification, treatment, and policy initiatives. Commentary on: Compulsive sexual behaviour disorder in the ICD-11 (Kraus et al., 2018). Journal of Behavioral Addictions, 7(2), 208-210. doi:10.1556/2006.7.2018.51

Hollander, E., \& Evers, M. (2001). New developments in impulsivity. Lancet, 358(9286), 949-950. doi:10.1016/S01406736(01)06114-1

King, D. L., \& Delfabbro, P. H. (2018). The concept of 'harm' in Internet gaming disorder. Journal of Behavioral Addictions, 23, 1-3. doi:10.1556/2006.7.2018.24

King, D. L., Delfabbro, P. H., Doh, Y. Y., Wu, A. M. S., Kuss, D. J., Pallesen, S., Mentzoni, R., Carragher, N., \& Sakuma, H. (2018). Policy and prevention approaches for disordered and hazardous gaming and Internet use: An international perspective. Prevention Science, 19(2), 233-249. doi:10.1007/s11121-0170813-1

Király, O., Griffiths, M. D., King, D. L., Lee, H.-K., Lee, S.-Y., Bányai, F., Zsila, Á., Takacs, Z. K., \& Demetrovics, Z. (2018). Policy responses to problematic video game use: A systematic review of current measures and future possibilities. Journal of Behavioral Addictions, 7(3), 503-517. doi:10.1556/2006. 6.2017 .050

Lee, E. W. J., Ho, S. S., \& Lwin, M. O. (2017). Explicating problematic social network sites use: A review of concepts, theoretical frameworks, and future directions for communication theorizing. New Media \& Society, 19(2), 308-326. doi:10.1177/1461444816671891

Lopez-Fernandez, O. (2015). How has Internet addiction research evolved since the advent of Internet gaming disorder? An overview of cyberaddictions from a psychological perspective. Current Addiction Reports, 2(3), 263-271. doi:10.1007/ s40429-015-0067-6

Männikkö, N., Ruotsalainen, H., Miettunen, J., Pontes, H. M., \& Kääriäinen, M. (2017). Problematic gaming behaviour and health-related outcomes: A systematic review and meta-analysis. Journal of Health Psychology. Advance online publication. 1-15. doi:10.1177/1359105317740414

Marsella, A. J., \& Yamada, A. M. (2010). Culture and psychopathology: Foundations, issues, directions. Journal of Pacific Rim Psychology, 4(2), 103-115. doi:10.1375/prp.4.2.103

Racine, E., \& Forlini, C. (2010). Cognitive enhancement, lifestyle choice or misuse of prescription drugs? Ethics blind spots in current debates. Neuroethics, 3(1), 1-4. doi:10.1007/s12152008-9023-7

Rochat, L., Maurage, P., Heeren, A., \& Billieux, J. (2019). Let's open the decision-making umbrella: A framework for conceptualizing and assessing features of impaired decision making in addiction. Neuropsychology Review, 29(1), 27-51. doi: 10.1007/s11065-018-9387-3

Saunders, J. B., Hao, W., Long, J., King, D. L., Mann, K., FauthBühler, M., Rumpf, H. J., Bowden-Jones, H., RahimiMovaghar, A., Chung, T., Chan, E., Bahar, N., Achab, S., Lee, H. K., Potenza, M., Petry, N., Spritzer, D., Ambekar, A., Derevensky, J., Griffiths, M. D., Pontes, H. M., Kuss, D., Higuchi, S., Mihara, S., Assangangkornchai, S., Sharma, M., Kashef, A. E., Ip, P., Farrell, M., Scafato, E., Carragher, N., \& Poznyak, V. (2017). Gaming disorder: Its delineation as an important condition for diagnosis, management, and prevention. Journal of Behavioral Addictions, 6(3), 271-279. doi:10.1556/2006.6.2017.039

Starcevic, V. (2017). Internet gaming disorder: Inadequate diagnostic criteria wrapped in a constraining conceptual model. Journal of Behavioral Addictions, 6(2), 110-113. doi:10.1556/ 2006.6.2017.012

Starcevic, V., \& Billieux, J. (2017). Does the construct of Internet addiction reflect a single entity or a spectrum of disorders? Clinical Neuropsychiatry, 14, 5-10.

Tversky, A., \& Kahneman, D. (1981). The framing of decisions and the psychology of choice. Science, 211(4481), 453-458. doi:10.1126/science. 7455683

Wéry, A., \& Billieux, J. (2017). Problematic cybersex: Conceptualization, assessment, and treatment. Addictive Behaviors, 64, 238-246. doi:10.1016/j.addbeh.2015.11.007 